\title{
Bit Error Rate pada Sistem MIMO MC-CDMA dengan Teknik Alamouti-STBC
}

\author{
Sekar Harlen', Eva Yovita Dwi Utami' ${ }^{2}$, Andreas A. Febrianto ${ }^{3}$ \\ Program Studi Teknik Elektro, \\ Fakultas Teknik Elektronika dan Komputer, \\ Universitas Kristen Satya Wacana, Salatiga \\ 1sekarharlen@gmail.com, 2eva.utami@staff.uksw.edu, 3andreas.febrianto@staff.uksw.edu
}

\begin{abstract}
Ringkasan
Pada makalah ini dilaporkan hasil penelitian sistem MIMO MC-CDMA dengan teknik Alamouti Space Time Block Code (STBC) menggunakan dua antena pengirim dan dua antena penerima. Kinerja sistem diukur dengan nilai Bit Error Rate (BER). Sistem yang diteliti disimulasikan dengan Matlab, dengan variasi jumlah pengguna, jumlah subpembawa, kecepatan pergerakan pengguna dan frekuensi Doppler. Hasil simulasi menunjukkan BER sistem MIMO MC-CDMA tidak mengalami penurunan yang tajam ketika jumlah pengguna dan frekuensi Doppler meningkat. Sedangkan simulasi dengan peningkatan jumlah subpembawa mampu menurunkan nilai BER sistem. Simulasi juga menunjukkan sistem MIMO-MC-CDMA memiliki kinerja sistem yang lebih baik dibandingkan sistem MCCDMA yang ditunjukkan dengan nilai BER sistem MIMO MC-CDMA berada pada orde $10^{-4}$ dan sistem MC-CDMA pada orde $10^{-1}$.
\end{abstract}

Kata kunci: MIMO, MC-CDMA, STBC

\section{Pendahuluan}

Sistem komunikasi pita lebar melalui jaringan nirkabel di masa sekarang dan mendatang harus mampu menyediakan jenis layanan yang beragam dengan kualitas layanan yang tidak kalah dengan teknologi transmisi melalui jaringan fisik (kabel dan serat optik). Teknik akses radio yang dipertimbangkan untuk memenuhi hal tersebut adalah pengembangan sistem komunikasi multiple input multipe output (MIMO) berbasis multi antena dan modulasi multicarrier code division multiple access (MC-CDMA) yang memungkinkan pengguna mengakses kanal secara simultan melalui subpembawa dengan kode penebar yang berbeda. Permasalahan yang harus dihadapi oleh sistem komunikasi radio bergerak adalah adanya propagasi jalur jamak yang menyebabkan isyarat di penerima terdiri dari isyarat langsung dan isyarat tertunda dengan magnitudo dan fase isyarat yang bervariasi serta waktu tunda yang berbeda-beda. Hal ini mengakibatkan terjadinya peredupan atau fading pada sistem komunikasi bergerak.

Sistem Code Division Multiple Access (CDMA) merupakan sistem komunikasi dengan menggunakan teknik spektrum tersebar yang mampu mentransmisikan informasi dari pengguna yang berbeda pada kanal frekuensi yang sama, sehingga diperoleh efisiensi lebar pita yang tinggi. Sistem CDMA diperbarui dengan teknik MC-CDMA. Pada MCCDMA, deretan kode penebar tidak diaplikasikan pada ranah waktu melainkan pada ranah frekuensi, kode chip penebar yang berbeda dipetakan pada setiap subpembawa. Setiap subpembawa memiliki data rate identik dengan data rate input aslinya, dengan 
demikian mengurangi kenaikan laju data karena penebaran dalam pita frekuensi yang lebih lebar [1]. Penelitian tentang MC-CDMA dalam [2] dan [3\} melaporkan unjuk kerja dan analisis BER pada sistem MC-CDMA. Peningkatan kinerja MC-CDMA diteliti melalui cara penggabungan MC-CDMA dengan sistem multicode pada [4]. Sistem CDMA dan MC-CDMA ini masih menemui kendala karena adanya peningkatan kapasitas pengguna dan banyaknya galat yang terjadi pada proses pengiriman dan penerimaan data yang disebabkan oleh penggunaan antena tunggal. Untuk mengatasi kendala ini dikembangkan sistem MIMO yang memiliki lebih dari satu antena pemancar dan penerima. Sistem ini dianggap efektif karena dapat meningkatkan kapasitas pengguna dan mengurangi terjadinya galat pada data yang diterima.

Teknik MIMO memberikan data rate lebih tinggi tanpa penambahan bandwidth dan dapat diperoleh laju galat yang lebih kecil, sehingga MIMO digabungkan dengan sistem MC-CDMA sebagaimana dilaporkan dalam [5], yang membahas kinerja MIMO-MCCDMA menggunakan modulasi FSK. Profil MIMO pada sistem nirkabel umumnya dapat direalisasikan dengan skema BELL labs architecture klasik (VBLAST-Vertical Bell Laboratories Space Time architecture) dan skema Space Time Block Codes (STBC)[6]. Pada [7] dibahas penelitian unjuk kerja MIMO-MC-CDMA menggunakan Space Time Frequeny Spreading (STFS) pada kanal frequency selective fading yang menunjukkan pencapaian maksimal penggunaan space diversity. Teknik V-Blast MIMO pada sistem MC-CDMA yang menggunakan dua jenis penyandian kanal dan skema ekualisasi yang berbeda diteliti pada [8]. Sedangkan skema STBC pada MIMO-MC-CDMA diteliti pada [9].

Dalam makalah ini dilaporkan hasil penelitian sistem MIMO-MC-CDMA dengan teknik Alamouti-STBC yang disimulasikan dengan Matlab. Analisis bit error rate dilakukan pada variasi jumlah pengguna, kecepatan pergerakan pengguna dan jumlah sub pembawa. Kinerja MIMO-MC-CDMA juga akan dibandingkan dengan sistem MCCDMA.

\section{Dasar Teori}

\subsection{Sistem $M C-C D M A$}

MC-CDMA merupakan teknik meletakkan isyarat yang akan dikirimkan dengan menggunakan beberapa frekuensi pembawa (subpembawa). Sistem ini melakukan proses penebaran (spreading) pada ranah frekuensi. Gambar 1 menunjukkan sistem MC-CDMA pada bagian pengirim.

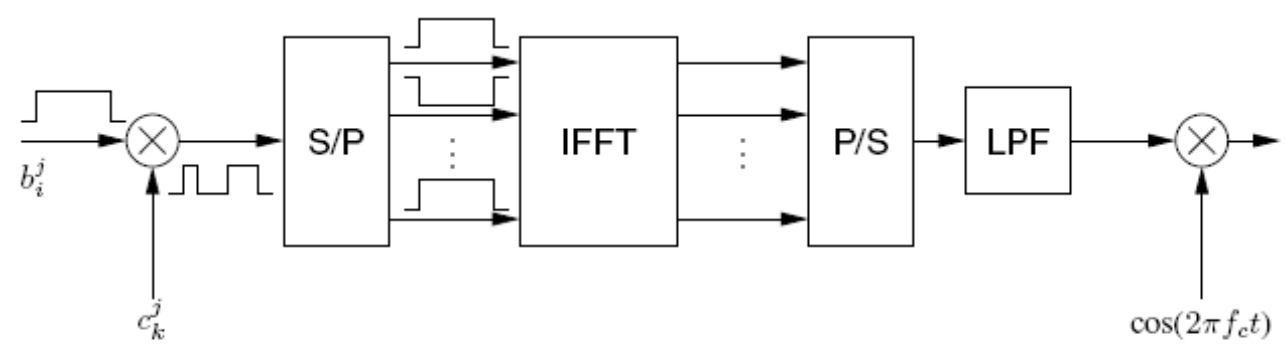

Gambar 1. Pemancar Sistem MC-CDMA [1]. 


\subsection{Sistem $M I M O$}

Sistem MIMO merupakan sistem transmisi (pengirim - penerima) dengan jumlah antena baik pengirim maupun penerima terdiri dari beberapa elemen antena ( $N$ antena pengirim dan $M$ antena penerima), secara umum dirumuskan sebagai berikut.

$$
y=H \cdot x+n
$$

dengan :

$y=$ isyarat yang diterima sejumlah $N$ antena;

$x=$ isyarat yang dipancarkan sejumlah $M$ antena;

$n=$ deraupada $N$ antena; dan

$H=$ kanal komunikasi radio yang menghubungkan pemancar dan penerima.

\subsection{Space Time Block Code (STBC)}

Teknik STBC pada sistem MIMO dikembangkan oleh Alamouti (1998) yang kemudian dikenal sebagai Alamouti-STBC. Dengan menggunakan $M=2$ antena pemancar dan $N=2$ antena penerima, matriks generator kode Alamouti ini diberikan sebagai

$$
G=\left[\begin{array}{cc}
x_{1} & x_{2} \\
-x_{2}^{*} & x_{1}^{*}
\end{array}\right]
$$

Isyarat $x_{1}$ dan $x_{2}$ ditransmisikan pada dua antena dalam slot waktupertama, dan isyarat $-x_{2}{ }^{*}$ dan $x_{1}{ }^{*}$ ditransmisikan pada dua antena dalam slot waktu kedua. Sehingga, kedua isyarat $x_{1}$ dan $x_{2}$ ditransmisikan dalam dua slot waktu. Skema transmisi AlamoutiSTBC ditunjukkan pada Gambar 2 dan notasi isyarat terimanya ditunjukkan pada Tabel 1.

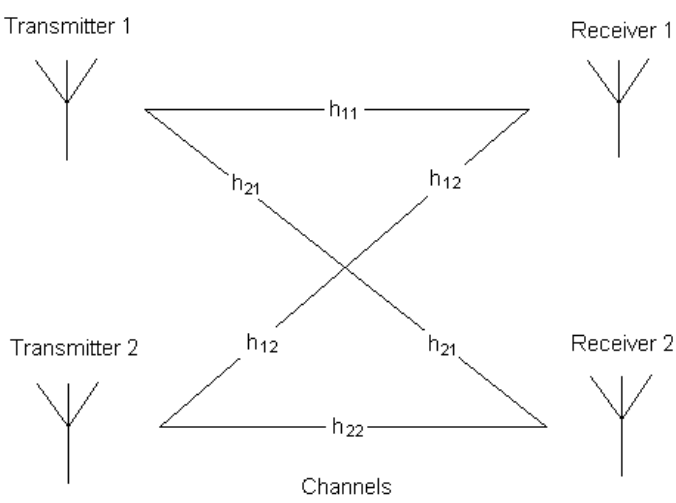

Gambar 2. Skema Transmisi Alamouti-STBC [10].

Tabel 1. Notasi Isyarat yang Diterima Menurut Skema Alamouti $2 x 2$.

\begin{tabular}{|l|c|c|}
\hline & $R_{x 1}$ & $R_{x 2}$ \\
\hline Saat $t$ & $y_{11}$ & $y_{21}$ \\
\hline Saat $t+T$ & $y_{12}$ & $y_{22}$ \\
\hline
\end{tabular}

Berdasarkan skema transmisi Alamouti-STBC di atas, persamaan isyarat yang diterima pada $R_{x 1}$ adalah :

$$
\begin{gathered}
y_{11}=h_{11} x_{1}+h_{12} x_{2}+n_{11} \\
y_{12}=-h_{11} x_{2}^{*}+h_{12} x_{1}^{*}+\mathrm{n}_{12}
\end{gathered}
$$

Persamaan isyarat yang diterima pada $R_{x 2}$ adalah :

$$
y_{21}=h_{21} x_{1}+h_{22} x_{2}+n_{21}
$$




$$
y_{22}=-h_{21} x_{2}^{*}+h_{22} x_{1}^{*}+n_{22}
$$

Sehingga pengawasandi $S T B C$ akan menerima kembali dua isyarat yang dikirimkan sebagai berikut :

$$
\begin{aligned}
& \widehat{x_{1}}=h_{11}^{*} y_{11}+h_{12} y_{12}^{*}+h_{21}^{*} y_{21}+h_{22} y_{22}^{*} \\
& \widehat{x_{2}}=h_{12}^{*} y_{11}-h_{11} y_{12}^{*}+h_{22}^{*} y_{21}-h_{21} y_{22}^{*}
\end{aligned}
$$

\section{Metode Penelitian}

\subsection{Pemodelan Sistem}

Pemodelan sistem diperlihatkan pada Gambar 3 yang dibagi dalam dua bagian besar yaitu sistem Pengirim dan Penerima.

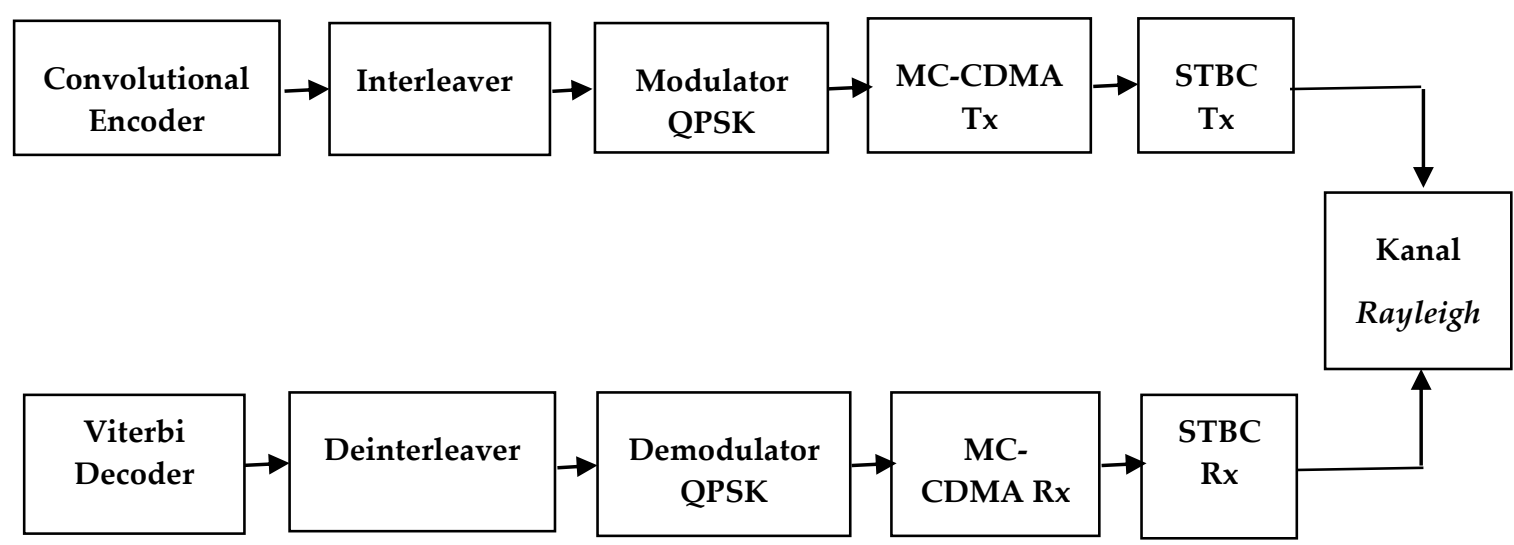

Gambar 3. Model Sistem MIMO-MC-CDMA

Pada pemodelan sistem, input ke sistem MIMO-MC-CDMA berupa data bit 1 dan 0 yang dibangkitkan secara acak. Data ini kemudian disandikan oleh encoder untuk proteksi terhadap adanya galat transmisi, menggunakan penyandi Konvolusional. Kemudian interleaver akan mengubah susunan data dengan cara data dibagi menjadi beberapa blok berbeda. Aliran bit masukan akan mengisi matriks interleaver dalam urutan baris demi baris sedangkan pada keluaran interleaver, bit-bit akan keluar sesuai urutan kolom. Data yang telah di-interleaving masuk ke modulator Quadrature Phase Shift Keying (QPSK), Blok serial-to-parallel berfungsi untuk mengkonversikan data serial menjadi data paralel, yang disesuaikan dengan jumlah subpembawa yang digunakan.

Pada sistem MC-CDMA, dilakukan beberapa tahapan proses pada data yang berasal dari modulator. Terdapat blok copier pada sistem MC-CDMA untuk menggandakan data yang dikirim agar data yang dikirim melalui masing-masing subpembawa adalah data yang sama. Pada spreader terjadi proses penebaran data pengguna yang akan dikirim dengan kode-kode penebar CDMA. Kode penebar yang digunakan pada sistem MCCDMA ini adalah $m$-sequence. Blok IFFT merupakan inti dari modulasi MC-CDMA, karena IFFT berfungsi sebagai modulator yang akan membangkitkan subpembawa yang saling orthogonal satu dengan yang lain.

Isyarat yang melewati kanal akan mengalami derau, sehingga pada simulasi akan ditambahkan Additive White Gaussian Noise (AWGN). Dalam simulasi kanal juga dimodelkan mengalami Rayleigh fading. Distribusi Rayleigh digunakan untuk 
menjelaskan perubahan waktu selubung isyarat yang mengalami peredupan yang diterima, atau selubung satu komponen jalur jamak. Selain itu kecepatan pergerakan pengguna akan mempengaruhi parameter modulasi frekuensi yang acak karena adanya Doppler shift. Perhitungan parameter dispersi waktu dan Doppler Shift didasarkan pada referensi [11]

Pada sistem penerima akan terjadi proses sebaliknya. Pada blok penerima MCCDMA dilakukan Fast Fourier Transform (FFT). FFT akan menggantikan proses demodulasi pada sistem MC-CDMA. Kode m-sequence yang digunakan pada modul spreader digunakan lagi pada proses despreader, tujuannya agar data tiap-tiap pengguna dapat diperoleh kembali. Blok Parallel to Serial berfungsi mengubah deretan data paralel menjadi deretan data serial. Agar kembali diperoleh data pada frekuensi baseband dilakukan demodulasi QPSK, yaitu mengalikan kembali dengan frekuensi pembawa seperti pada blok modulasi QPSK. Pada deinterleaver, bit-bit akan diurutkan kembali seperti urutan semula sebelum proses interleaving. Untuk mengoreki adanya galat yang terjadi dilakukan pengawasandian menggunakan pengawasandi Konvolusional yang diimplementasikan menggunakan algoritma Viterbi. Algoritma ini dapat menemukan dan mengoreksi adanya galat transmisi.

\subsection{Parameter Simulasi}

Dalam menyimulasikan sistem MIMO-MC-CDMA, digunakan parameter-parameter simulasi dan nilai-nilainya ditampilkan pada Tabel 2.

Tabel 2. Parameter Simulasi

\begin{tabular}{|l|c|}
\hline \multicolumn{1}{|c|}{ Parameter Simulasi } & Nilai Parameter \\
\hline Jumlah bit data & 1024 \\
\hline Frekuensi pembawa & $900 \mathrm{MHz}$ \\
\hline Jumlah pengguna & $10,20,30$ \\
\hline Jumlah subpembawa & 8,16 \\
\hline Frekuensi Doppler & $33,33 \mathrm{~Hz}, 41,67 \mathrm{~Hz}, 66,67$ \\
& $\mathrm{~Hz}, 83,33 \mathrm{~Hz}$ \\
\hline Kecepatan pergerakan & $40 \mathrm{~km} / \mathrm{jam}, 50 \mathrm{~km} / \mathrm{jam}$ \\
pengguna & $030 \mathrm{~dB}$ \\
\hline SNR & \\
\hline
\end{tabular}

\section{Hasil dan Pembahasan}

\subsection{Hasil Simulasi berdasarkan Jumlah Pengguna}

Simulasi ini dilakukan untuk melihat pengaruh jumlah pengguna terhadap kinerja sistem MIMO MC-CDMA pada kanal multipath Rayleigh fading dengan jumlah bit data yang ditransmisikan adalah 1024 bit. Variasi jumlah pengguna yang digunakan adalah 10, 20, dan 30 pengguna.

Dari hasil simulasi pada Gambar 4 terlihat bahwa kinerja sistem untuk variasi jumlah pengguna yang berbeda tidak menunjukkan perbedaan yang signifikan. Hal ini menunjukkan bahwa sistem MIMO MC-CDMA mampu mengatasi variasi banyaknya jumlah pengguna. Semakin banyak jumlah pengguna, nilai $B E R$ sistem pada $S N R$ yang sama akan akan meningkat. Misalnya pada $S N R 30 \mathrm{~dB}$, nilai $B E R$ yang didapat adalah $1,9094 \times 10^{-4}, 1,9271 \times 10^{-4}$, dan $1,9401 \times 10^{-4}$.

Peningkatan kecepatan pengguna sebesar $10 \mathrm{~km} / \mathrm{jam}$ tidak terlalu mempengaruhi nilai $B E R$ yang didapat. Terlihat bahwa nilai BER yang dihasilkan saat SNR $5 \mathrm{~dB}$ dan 30 
$\mathrm{dB}$ tidak berbeda jauh dengan nilai $B E R$ pada saat kecepatan pengguna $40 \mathrm{~km} / \mathrm{jam}$. Saat SNR $30 \mathrm{~dB}$, nilai $B E R$ yang didapat untuk jumlah pengguna 10, 20, dan 30 berturut-turut adalah $2,0052 \times 10^{-4}, 2,0703 \times 10^{-4}$, dan $2,1007 \times 10^{-4}$.

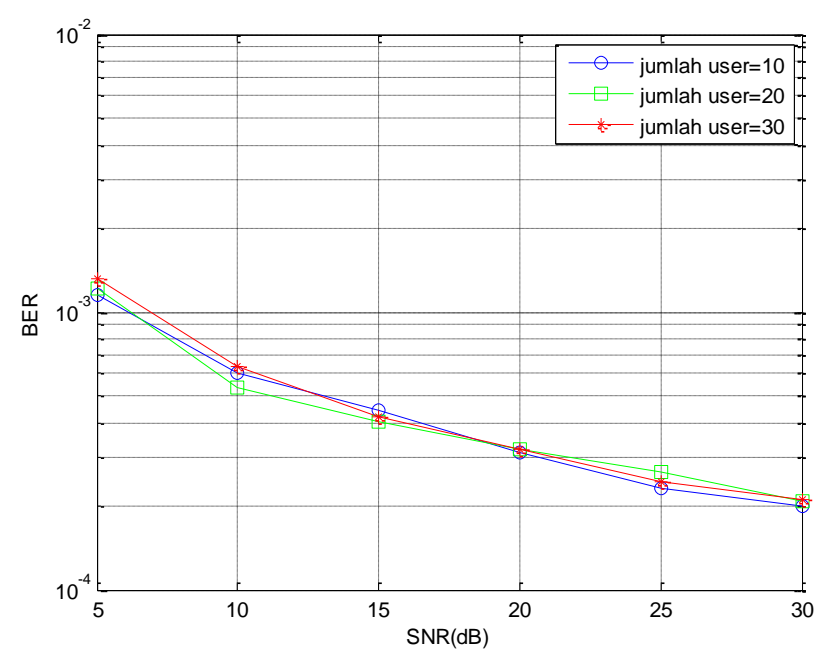

$\{a\}$

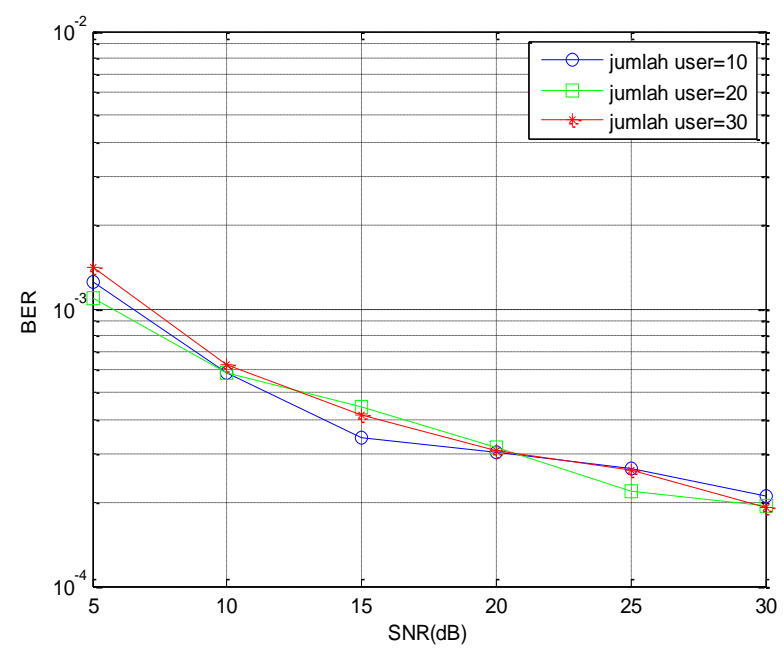

(b)

Gambar 4. Grafik Kinerja MIMO MC-CDMA pada $f_{c}=900 \mathrm{MHz}$ dan (a) kecepatan kendaraan $v=40 \mathrm{~km} / \mathrm{jam}$, (b) kecepatan kendaraan $v=50 \mathrm{~km} / \mathrm{jam}$

\subsection{Hasil Simulasi berdasarkan Frekuensi Doppler}

Berdasarkan Gambar 5, 6, dan 7 dapat dilihat pengaruh frekuensi Doppler terhadap kinerja sistem MIMO MC-CDMA. Setiap peningkatan frekuensi Doppler juga diikuti dengan peningkatan $S N R$ yang diberikan untuk mencapai nilai $B E R$ yang rendah. Semakin tinggi kecepatan pengguna, frekuensi Doppler yang dihasilkan juga meningkat. Tingginya frekuensi Doppler menyebabkan frekuensi modulasi acak. Secara berturutturut nilai $B E R$ yang dihasilkan dengan variasi frekuensi Doppler $33,33 \mathrm{~Hz}, 41,67 \mathrm{~Hz}$, $66,67 \mathrm{~Hz}$, dan 83,33 $\mathrm{Hz}$ dengan jumlah pengguna 10 pada $S N R 5 \mathrm{~dB}$ adalah 0,0012, 0,0012,

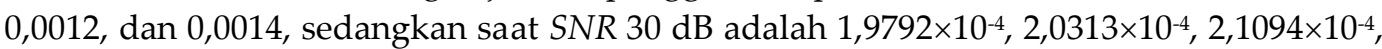
dan $2,1354 \times 10^{-4}$. 


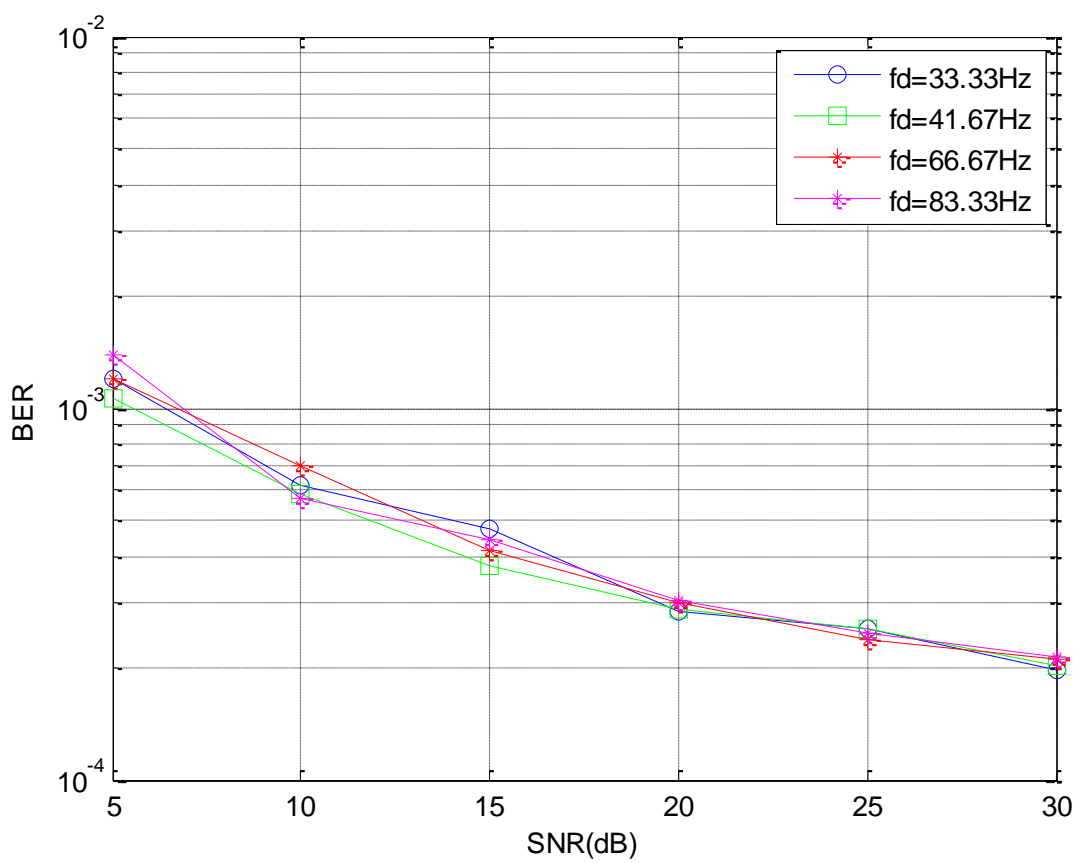

Gambar 5. Grafik Kinerja MIMO MC-CDMA Berdasarkan Frekuensi Doppler dengan 10 Pengguna.

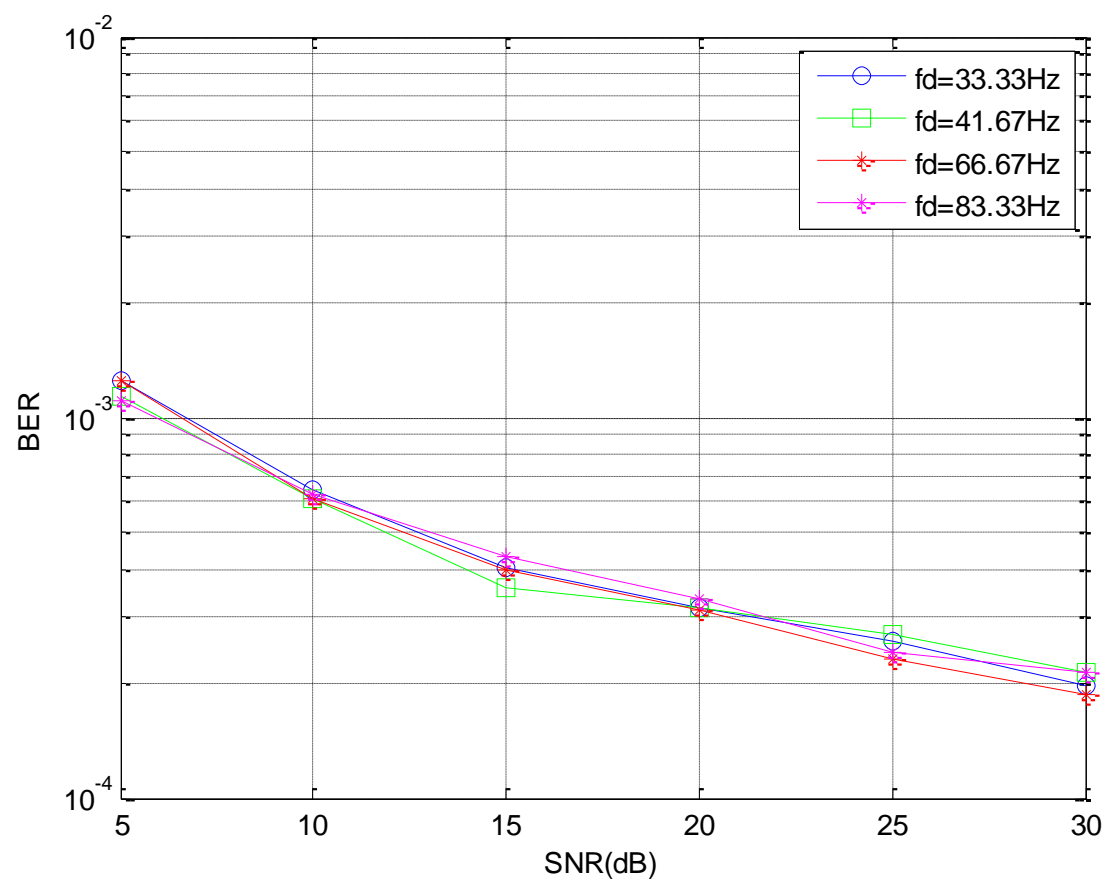

Gambar 6. Grafik Kinerja MIMO MC-CDMA Berdasarkan Frekuensi Doppler dengan 20 Pengguna. 


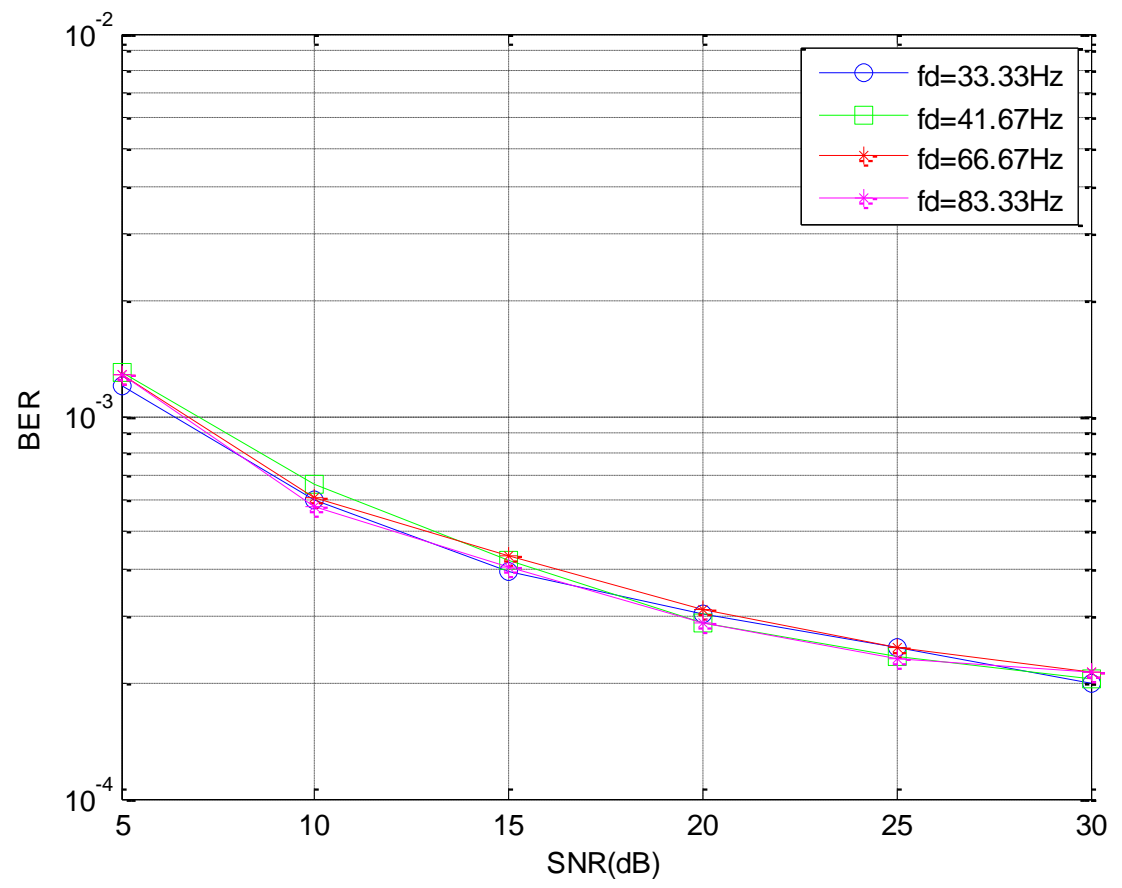

Gambar 7. Grafik Kinerja MIMO MC-CDMA Berdasarkan Frekuensi Doppler dengan 30 Pengguna.

\subsection{Hasil Simulasi Berdasarkan Jumlah Subpembawa}

Berdasarkan Gambar 8, terlihat bahwa jumlah subpembawa mempengaruhi kinerja sistem MIMO MC-CDMA. Jumlah subpembawa 16 menghasilkan kinerja $B E R$ yang lebih baik dibandingkan dengan 8 subpembawa. Dengan menggunakan 16 subpembawa diperoleh $B E R$ sistem pada $S N R 30 \mathrm{~dB}$ sebesar 2,0790 $\times 10^{-4}$ dan dengan 8 subpembawa sebesar $7,5521 \times 10^{-4}$. Hal ini disebabkan semakin banyak subpembawa yang digunakan, maka akan semakin banyak kode yang dibangkitkan, sehingga pemilihan isyarat informasi dengan peredupan minimal dapat dicapai. Pengamatan dan perhitungan BER pada sistem menunjukkan bahwa pada sistem dengan 16 subpembawa mempunyai nilai $B E R$ 5,6 dB lebih kecil daripada BER sistem dengan 8 subpembawa, jika keduanya dilihat pada $S N R 30 \mathrm{~dB}$.

\subsection{Perbandingan Kinerja Sistem MIMO MC-CDMA dan MC-CDMA}

Berdasarkan Gambar 9, terlihat bahwa nilai BER sistem MIMO MC-CDMA secara keseluruhan lebih rendah dibandingkan sistem MC-CDMA untuk variasi pengguna yang berbeda. Perbedaan kinerja sistem yang dihasilkan untuk 10 pengguna pada SNR $30 \mathrm{~dB}$ adalah nilai BER sistem MC-CDMA sebesar 0,1424 dan MIMO MC-CDMA sebesar $1,9792 \times 10^{-4}$. Peningkatan kinerja sistem ini dipengaruhi oleh karena sistem MIMO menggunakan antena jamak pada sisi pengirim dan penerima 


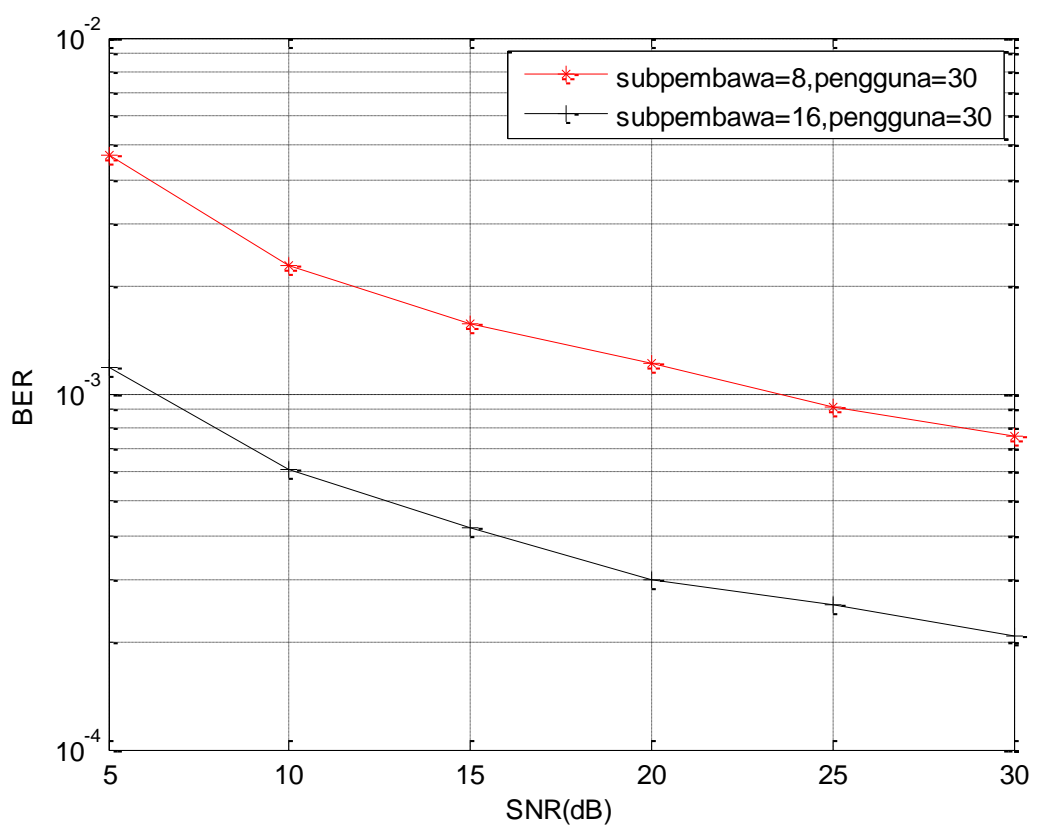

Gambar 8. Grafik Kinerja MIMO MC-CDMA Berdasarkan Jumlah Subpembawa dengan 30 Pengguna.

Nilai penurunan BER maksimal yang terjadi pada $v=40 \mathrm{~km} / \mathrm{jam}$ yaitu sebesar 0,3343

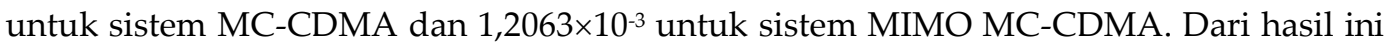
terlihat bahwa sistem MIMO MC-CDMA dengan peningkatan jumlah pengguna mampu menghasilkan penurunan nilai BER yang maksimal. Sedangkan untuk sistem MC-CDMA, meningkatnya jumlah pengguna menghasilkan penurunan nilai BER yang semakin kecil.

Penurunan nilai BER maksimal untuk sistem MC-CDMA terjadi pada kondisi dengan jumlah pengguna 10 pada $f_{\mathrm{d}}=33,33 \mathrm{~Hz}$ yaitu sebesar 0,3400. Sedangkan untuk sistem MIMO MC-CDMA, penurunan nilai BER maksimal terjadi pada kondisi dengan jumlah pengguna 10 pada $f_{\mathrm{d}}=83,33 \mathrm{~Hz}$ yaitu sebesar $1,1865 \times 10^{-3}$. Hasil ini menunjukkan bahwa untuk jumlah pengguna tertentu, sistem MIMO MC-CDMA mampu mengatasi tingginya frekuensi Doppler yang dihasilkan. 


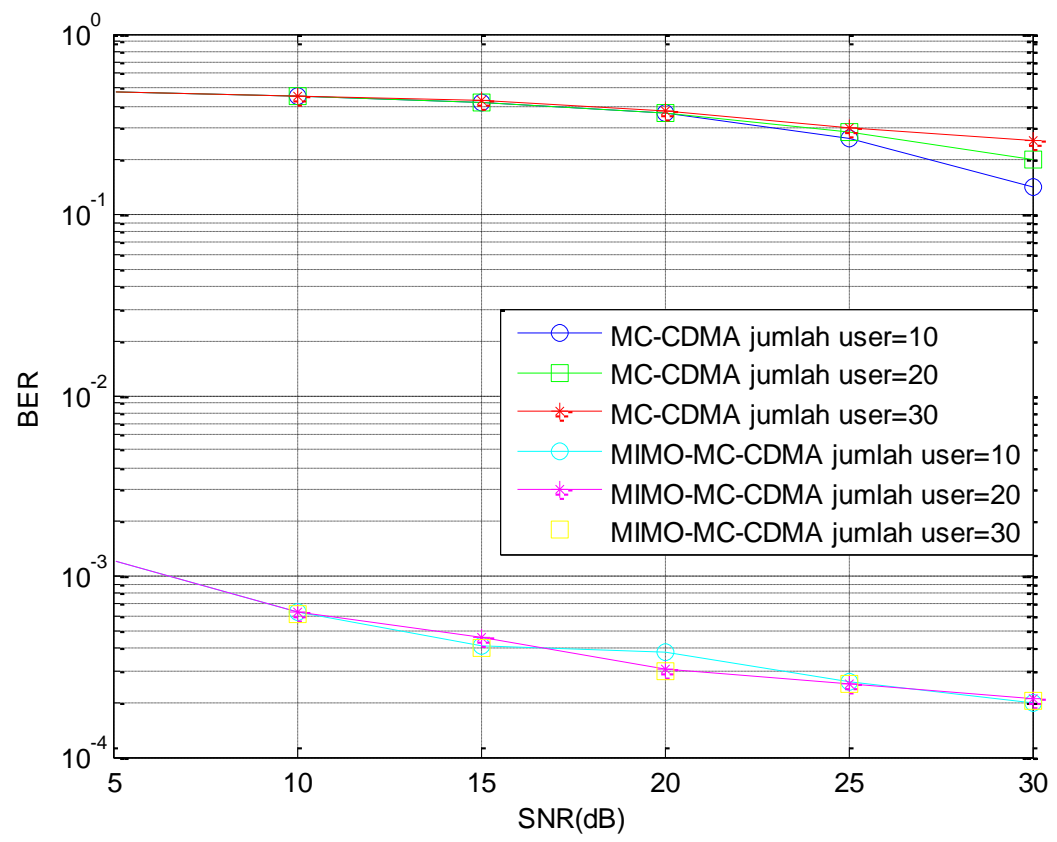

Gambar 9. Kinerja MC-CDMA dan MIMO MC-CDMA, $v=40 \mathrm{~km} / \mathrm{jam}, f_{d}=33,33 \mathrm{~Hz}$

\section{Kesimpulan}

Berdasarkan keseluruhan tahapan simulasi dan analisis yang telah dilakukan dapat disimpulkan hal-hal sebagai berikut. Sistem MIMO MC-CDMA memiliki kinerja yang lebih baik dibandingkan sistem MC-CDMA. Hal ini ditunjukkan dengan nilai BER sistem MIMO MC-CDMA berada pada orde $10^{-4}$ sedangkan sistem MC-CDMA berada pada orde $10^{-1}$.

Sistem MC-CDMA mampu mengatasi pengaruh pergerakan pengguna. Sehingga, ketika sistem MC-CDMA ini digabungkan dengan sistem MIMO menjadi MIMO MCCDMA, variasi kecepatan gerak pengguna yang menyebabkan pergeseran frekuensi Doppler tidak banyak mengubah nilai BER yang dihasilkan. Penurunan BER maksimal terjadi pada 10 pengguna dengan $f_{\mathrm{d}}=33,33 \mathrm{~Hz}$ untuk sistem MC-CDMA sebesar 0,3400 dan untuk sistem MIMO MC-CDMA terjadi pada $f_{\mathrm{d}}=83.33 \mathrm{~Hz}$ sebesar $1,1865 \times 10^{-3}$.

Penambahan jumlah subpembawa akan memperbaiki kinerja sistem. Sistem MCCDMA dengan 16 subpembawa menurunkan BER sebesar 0,98 dB dari sistem dengan 8 subpembawa. Sementara untuk sistem MIMO-MC-CDMA dengan 16 subpembawa memberikan penurunan nilai BER 5,6 dB dari sistem dengan 8 subpembawa.

\section{Daftar Pustaka}

[1] L. Hanzo, T. Keller, OFDM and MC-CDMA: A Primer, England: John Wiley and Sons, Ltd., 2006

[2] R.Choubey, R. Mohan, S. Sharma, "Performance Analysis of Generalized MC DSCDMA System", International Journal of Advanced Computer Research, Vol. 3 No. 2, June 2013, pp 159-162 
[3] R.Choubey, R. Mohan, S. Sharma, "Result Analysis of Bit-Error Rate (BER) of the MC DS-CDMA System", International Journal of Advanced Computer Research, Vol. 3 No. 3, 11 September-2013, pp. 411-415

[4] E.Y.D. Utami, “Unjuk Kerja Multi-code Multicarrier CDMA pada Kanal Multipath Fading", Jurnal Ilmiah Elektroteknika Techne, vol. 4, no. 2, Oktober 2005, pp. 73-81

[5] M. Jangalwa, V. Tokekar, "Performance of MIMO MC-CDMA system with PSK modulation technique", Proc. IEEE International Conference on Signal Processing and Integrated Networks (SPIN), 2016, 11-12 February 2016

[6] K.S.Vishvaksenan, R. Seshasayanan, "Performance Analysis of MIMO Assisted Interleave Division Multiple Access System with Multi-user Detection', International Journal of Computer Applications (0975 - 8887) Volume 11- No.4, December 2010

[7] H. Dahman and Y. Shayan, "Performance evaluation of space-time-frequency spreading for MIMO OFDM-CDMA systems", EURASIP Journal on Advances in Signal Processing 2011, 2011

[8] M.Haque, M. F. Sharmin and S. E. Ullah, "Secured data transmission in a V-Blast encoded MIMO MC-CDMA wireless communication system", International Journal of Information \& Network Security (IJINS) Vol. 2, No. 3, June 2013, pp. 245 252

[9] D. Faiza, "Simulasi Kombinasi Space Time Block Code Dengan Teknik MC-CDMA Pada sistem MIMO Menggunakan MATLAB 7.0", Jurnal Teknologi Informasi dan Pendidikan., Universitas Negeri Padang, 2011.

[10]Aragorn., http://dsplog.com Space Time Block Code, diakses tanggal 9 Agustus 2014.

[11]T.S. Rappaport, Wireless Communications Principles and Practice, Second Ed., Prentice Hall PTR, 2002. 
